\title{
Enhancing Growth of Vigna radiata in the Presence of Pseudomonas aeruginosa Biopolymer and Metarhizium anisopliae Spores
}

\author{
Bhagwan N. Rekadwad, Chandrahasya N. Khobragade, \\ Vishnu G. Jadhav, and Siddheswar U. Kadam \\ School of Life Sciences, Swami Ramanand Teerth Marathwada University, Nanded 431606, India \\ Correspondence should be addressed to Bhagwan N. Rekadwad; rekadwad@gmail.com
}

Received 26 July 2016; Revised 13 November 2016; Accepted 20 November 2016

Academic Editor: Tibor Janda

Copyright ( 2016 Bhagwan N. Rekadwad et al. This is an open access article distributed under the Creative Commons Attribution License, which permits unrestricted use, distribution, and reproduction in any medium, provided the original work is properly cited.

\begin{abstract}
Exopolysaccharide producing Pseudomonas aeruginosa NCIM 2945 (PANCL) belonging to gamma-proteobacterium and entomopathogenic fungus Metarhizium anisopliae MCC 1129 (MAMCC) belonging to Ascomycota were studied for their morphological features biochemical characteristics and plant growth promotion ability. Optimum growth of PANCL was recorded after $24 \mathrm{~h}$ at temperature $30^{\circ} \mathrm{C}$ and $\mathrm{pH}$ 7.0. Gram-negative PANCL appeared as white in color, one mm size, circular, opaque, and nonconsistent elevated colonies with entire margin. It has utilized dextrose, fructose, maltose, and sorbitol as carbon source and produced acid in the medium. PANCL was sensitive to Polymyxin B (300 $\mu \mathrm{gm} / \mathrm{disc})$ followed by Neomycin $(30 \mu \mathrm{gm} / \mathrm{disc})$, Gentamycin $(10 \mu \mathrm{gm} / \mathrm{disc})$, and Chloramphenicol $(30 \mu \mathrm{gm} / \mathrm{disc})$. PANCL has secreted extracellular lipase, amylase, protease, and exopolysaccharides (EPS). Another fungal strain MAMCC sporulated after $168 \mathrm{~h}$ at temperature $30^{\circ} \mathrm{C}$ and $\mathrm{pH} 7.0$. MAMCC has septate-white mycelium and bears dirty green colored spores. Growth of MAMCC was enhanced in the presence of Neem and Karela-Amla oil $(0.1 \mathrm{~mL}$ each). Extracellular polysaccharide produced by PANCL and spores of MAMCC promoted growth of dicotyledon Vigna radiata (Mung) individually as well as in consortium. Considerable increase in dry weight of Vigna radiata was recorded. Thus, reported PANCL and MAMCC strains have promoted growth Vigna radiata and may be a solution for sustainable agriculture.
\end{abstract}

\section{Introduction}

A group of microorganisms are frequently appreciated for their applications in enhanced primary productivity of crop plants and increasing their induced systemic resistance. These are called plant growth promoting rhizobacteria (PGPR). This PGPR-triggered plant growth, defense, biocontrol of pests, and plant pathogens depend on a variety of biotic/abiotic and genetic factors [1]. Complex communities of PGPR along with other beneficial eukaryotes (especially fungi) are inhabiting plant root zone and rhizospheric soil. Beneficial free-living soil bacteria and fungi are generally having role as the plant growth promoting microorganisms with plants, which is sometimes different than symbiotic association. Some strains actively promote plant growth whereas others have no measurable effect on plants. Being an inert microorganism living in rhizospheric arable in the vicinity of plants, some microscopic species such as entomopathogenic fungi present in soil and promote plant growth.

Bacterium Pseudomonas aeruginosa (P. aeruginosa) is capable of producing biopolymer under a wide range of stressful conditions. Recently, Jiang et al. investigated Pseudomonas strain for its plant growth promoting ability $[2,3]$. There is little information about the roles of Pseudomonas aeruginosa NCIM2945 in plant growth promotion. Unlike $P$. aeruginosa, fungal strain Metarhizium anisopliae (M. anisopliae) is entomopathogenic infects insects. Recently, it is observed that Metarhizium species was found to be good plant rhizosphere associates. Reports state that some species 
of Metarhizium are multifactorial plant growth promoters [4]. Once the fungal spore attached the insect body, it germinates and starts to protrude its mycelium from outer skeleton to inside body of insect, causing the insect to die [5-8]. Bioprospecting of such agriculturally important microorganisms is the necessity of the entire world for next Green Revolution, which is the promising solution for sustainable agriculture. Hence, it is necessary to understand the role of PGPR and PGPR-biomolecules and other microorganisms in plant growth. In this research paper, these properties of $P$. aeruginosa and $M$. anisopliae were examined for their role in plant growth promoting activity and increase in biomass.

\section{Materials and Methods}

2.1. Bacterial and Fungal Culture. Viable bacterial culture of Pseudomonas aeruginosa NCIM 2945 (PANCL) and Metarhizium anisopliae MCC 1129 (MAMCC) was purchased from National Culture of Industrial Microorganisms (NCIM), National Chemical Laboratory (NCL), Pune, and Microbial Culture Collection (MCC), and National Centre for Cell Science (NCCS), Pune, respectively. Activated culture of PANCL and sporulated MAMCC were used for every experiment. PANCL was subcultured on nutrient agar $(\mathrm{pH}$ 7.0) and incubated at temperature $30^{\circ} \mathrm{C}$ for 24 hours, while MAMCC was subcultured on potato dextrose agar (PDA) and incubated at $30^{\circ} \mathrm{C}$ for 168 hours.

\subsection{Characterization of PANCL}

Morphological Characterization. Activated culture was used for morphological characterization of PANCL. Colony characteristics were recorded. Gram nature was determined.

Carbohydrate Utilization Test. Sugars (fructose, sucrose, sorbitol, dextrose, and maltose) utilization test was performed. Sterile peptone water added with $0.5 \%$ sugar was inoculated and incubated at $30^{\circ} \mathrm{C}$ for 48 hours. Formation of acid changes color of peptone water from red to yellow indicating positive result.

Antibiotic Sensitivity Test. Bacterial mat was prepared on plate. Antibiotic discs-Bacitracin (B), Chloramphenicol (C), Penicillin (P), Gentamycin (GEN), Polymyxin B (PB), and Neomycin $(\mathrm{N})$ - were placed aseptically and gently tapped on that prepared agar surface. Plates were incubated at $30^{\circ} \mathrm{C}$ for 24 hours. Zone of clearance was measured in $\mathrm{mm}$.

Lipase Test. $1 \mathrm{~mL}$ of tributyrate was taken along with $100 \mathrm{~mL}$ nutrient agar. $0.1 \mathrm{~mL}$ of bacterial culture then spread on agar surface. Petri plates were incubated for 24 hours at $30^{\circ} \mathrm{C}$. Change in color to green indicates positive test.

Amylase Test. Starch agar medium was prepared. $0.1 \mathrm{~mL}$ of bacterial culture then spread on prepared agar surface. Petri plates were incubated for 24 hours at $30^{\circ} \mathrm{C}$. Starch agar plates were flooded with iodine. Unhydrolysed starch appeared blue and hydrolysed starch appeared white indicating positive test.
Protease Test. Skim milk agar (SMA) was prepared. Bacterial culture was streaked on SMA. All plates were incubated for 24 hours at $30^{\circ} \mathrm{C}$. Zone of clearance on agar media indicates positive test.

Catalase Test. One drop of 3\% hydrogen peroxide was placed on a clean slide. Loop-full bacterial culture was taken and suspended in hydrogen peroxide. Release of oxygen bubbles indicates positive test $[9,10]$.

\subsection{Characterization of MAMCC}

Slide Culture Method. Potato dextrose agar plates were prepared. Aseptically, using a sterile blade PDA block $(1 \times 1 \mathrm{~mm})$ was prepared and placed on sterile slide in the sterile petri plate containing sterile cover slip. The four corners of the PDA block were inoculated with MAMCC spores. Sterile cover slip was placed on the inoculated PDA block and tapped gently. Inoculated petri plates were incubated at $30^{\circ} \mathrm{C}$ for 168 hours. Once sporulation occurred, the cover slip from agar block was taken and stained using lactophenol cotton blue stain and observed under light microscope first under 10x objective and then switched to $40 \mathrm{x}$ objective for better observation.

Radial Growth Assay. PDA plates and MAMCC spore suspension were prepared. PDA plates were spot inoculated and incubated at $30^{\circ} \mathrm{C}$ for 10 days. Radial growth in centimetre $(\mathrm{cm})$ was measured and results were recorded in lab book [1113].

Effect of Neem and Karela-Amla oil on MAMCC: $0.1 \mathrm{~mL}$ oil was taken on the PDA surface. Plates were allowed to stand ideal for 10 minutes. This allowed oil to diffuse in the nutrient medium. Effect of Neem oil and Karela-Amla oil on MAMCC was studied using radial growth assay as mentioned in former steps.

2.4. Submerged State Production of Polysaccharide. Cooled sterile $300 \mathrm{~mL}$ glucose nutrient broth was inoculated with $5 \%$ of inoculum of PANCL. Inoculated flasks were incubated in shaking incubator for 62 hours at $120 \mathrm{rpm}$ speed and at temperature $30^{\circ} \mathrm{C}$.

2.5. Polysaccharide Production Qualitative Test: Fehling's Test. NCL: $15 \mathrm{~mL}$ of solution A, $15 \mathrm{~mL}$ of solution B, $2 \mathrm{~mL}$ of mixture, and 3 drops of test sample were placed in test tube. This reaction set was incubated in water bath at $60^{\circ} \mathrm{C}$ for 10 minutes. Formation of green suspension and a red precipitate indicate positive test.

2.6. Partial Purification of Polysaccharide Produced by PANCL. Submerged state production media were harvested after $62 \mathrm{~h}$ by centrifugation at $10,000 \mathrm{rpm}$ speed for 20 minutes at temperature $4^{\circ} \mathrm{C}$. Supernatant was collected and poured in $50 \mathrm{KD}$ dialysis bag and dialyzed at $23^{\circ} \mathrm{C}$ overnight. After overnight dialysis content was taken with ethanol in 1:2 proportion and 7\% KCL was added. This content was kept in refrigerator for $24 \mathrm{~h}$ at $4^{\circ} \mathrm{C}$. Ethanol: KCL precipitation was followed by centrifugation at 10,000 rpm for 30 minutes. 
This time pellet was collected and dissolved in $100 \mathrm{~mL}$ sterile distilled water $[14,15]$. This partially purified biopolymer solution was used for further experiments.

2.7. MAMCC Inoculum Preparation. PDA plates were spread with MAMCC spore suspension and incubated at $30^{\circ} \mathrm{C}$ for $168 \mathrm{~h}$. After completion on incubation period, sporulated fungus was harvested in the sterile physiological saline $(0.85 \mathrm{~g}$ sodium chloride dissolved in little distilled water and made up to $100 \mathrm{~mL}$. Sterility of prepared saline was checked through autoclaving).

2.8. MAMCC Spore Counting Using Haemocytometer. Number of spores per litre was determined using haemocytometer.

\subsection{Plant Growth Promotion Study}

Treatment to Soil. Fertile arable (soil) was collected, cleaned, and sterilized by autoclaving at $121^{\circ} \mathrm{C} / 15 \mathrm{lbs}$ pressure. Sterile arable was used for further experiments.

Selection of Seeds. Vigna radiata seeds were purchased from local market. Good quality and healthy seeds were selected on the basis of good appearance, size, and external characteristics and appearance.

\section{Plant Growth Promotion Assay Using PANCL}

Preparation of Pot and Sowing of Seeds. Three pots each containing $2 \mathrm{Kg}$ sterile soil were taken and labelled as control, experimental-I, and experimental-II. 50 seeds of Vigna radiata per pot have to be added in each pot. Seeds were treated with PANCL biopolymer solution (EPS). Control pot was kept untreated. Seeds added in experimental pot-I were gently rubbed with mixture of biopolymer and glycerol $(1: 1)$. In case of experimental pot-II, biopolymer-glycerol mixture was sprinkled on soil and mixed. Seeds were sowed in all pots and covered with $1 \mathrm{~cm}$ thick layer of same soil of each pot. Equal quantity of water was added to each pot and all physical parameters were uniformly maintained for all pots.

Preparation of Pot. Five pots each containing $2.5 \mathrm{Kg}$ sterile soil were taken and labelled as control, experimentalI, experimental-II, experimental-III, experimental-IV, and experimental-V.

Exp. pot-1: control pot-sterile soil without any organisms.

Exp. pot-2: spore suspension mixed with soil.

Exp. pot-3: spore suspension and Neem leaves (3g powder) mixed with soil.

Exp. pot-4: spore suspension and Behada churn (3 g powder) mixed with soil.

Addition of Spore Suspension to Treated Soil. Spore suspension of $M$. anisopliae was sprinkled on soil and mixed. Control pot-I was kept untreated.

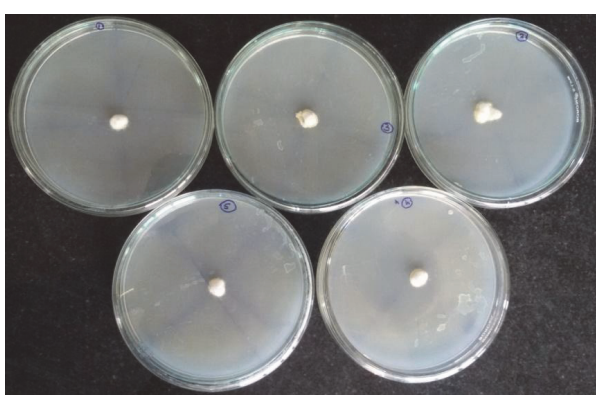

FIGURE 1: MAMCC: radial growth assay.

Plant Growth Measurement. Growth of plants in each pot was recorded after fixed time interval, that is, after every 48 hours [16].

Plant Growth Promotion Assay Using PANCL Exopolysaccharide and MAMCC Spore Consortium. Consortium of PANCL and MAMCC was prepared. Both cultures were taken in $1: 1$ ratio. $50 \mathrm{~mL}$ of consortium was sprinkled on soil and uniformly mixed. 50 seeds were sowed in experimental pot. All physical and environmental parameters were maintained as per former steps. Germination of seeds and growth of plants were observed after every $48 \mathrm{~h}$ up to 17 days. Exp. pot1 is control pots without any organisms. Exp. pot-5 is spore suspension and bacterial suspension mixed with soil $(1: 1)$.

\section{Results}

3.1. Morphological and Biochemical Characterization and Properties of PANCL and MAMCC. Activated cultures of PANCL and MAMCC were used for plant growth promoting characteristics (PGPC) of PANCL and MAMCC. PANCL appeared as $1 \mathrm{~mm}$, circular, white elevated colonies with entire margin. Gram-negative PANCL colonies were opaque and nonconsistent. PANCL showed optimum temperature $30^{\circ} \mathrm{C}$ and $\mathrm{pH}$ 7.0. PANCL utilized dextrose, fructose, maltose, and sorbitol as carbon source and produced acid in the medium. PANCL was sensitive to Polymyxin B (300 $\mu \mathrm{gm} / \mathrm{disc})$, Neomycin $(30 \mu \mathrm{gm} / \mathrm{disc})$, and Gentamycin (10 $\mu \mathrm{gm} /$ disc) followed by Chloramphenicol $(30 \mu \mathrm{gm} / \mathrm{disc})$. PANCL produced extracellular lipase, amylase, and protease enzymes. PANCL was examined for its extracellular biopolymer producing ability. Qualitative Fehling's test showed positive results, which indicate that PANCL is polysaccharide producing strain (Table 1). Entomopathogenic fungus MAMCC was examined for its growth and PGPC. Slow growing MAMCC appeared as white, septate, and multinucleated mycelium $48-72 \mathrm{~h}$ of incubation at temperature $30^{\circ} \mathrm{C}$ and $\mathrm{pH}$ 7.0. Sporulation was started after $72 \mathrm{~h}$ and full sporulation was recorded after $168-240 \mathrm{~h}$. Spores were dirty green in color which gives dirty greenish-black mycelium with some newly formed interweave white and cottony hyphae. We have studied effects of Neem and Karela-Amla oil (Ayurvedic formulations) on the growth and sporulation of MAMCC. It was recorded that the Neem and Karela-Amla oil enhanced the growth of fungus MAMCC (Figures 1-2, Table 2). 
TABLE 1: Morphological biochemical characteristics of Pseudomonas aeruginosa NCIM 2945 (PANCL).

\begin{tabular}{|c|c|}
\hline Parameter & Results \\
\hline Size & $0.1 \mathrm{~mm}$ \\
\hline Shape & Circular \\
\hline Color & Dirty white \\
\hline Margin & Entire \\
\hline Opacity & Opaque \\
\hline Consistency & Nonconsistent \\
\hline Elevation & Elevated \\
\hline Gram nature & Gram-negative \\
\hline Sucrose & - \\
\hline Sorbitol & + \\
\hline Dextrose & + \\
\hline Maltose & + \\
\hline Fructose & + \\
\hline Lipase & + \\
\hline Catalase & + \\
\hline Amylase & + \\
\hline Protease & + \\
\hline \multicolumn{2}{|c|}{ Antibiotic sensitivity test (zone of inhibition in $\mathrm{mm}$ ) } \\
\hline Bacitracin (B) & $\mathrm{R}$ \\
\hline Chloramphenicol (C) & 4 \\
\hline Penicillin (P) & $\mathrm{R}$ \\
\hline Gentamycin (GEN) & 9 \\
\hline Polymyxin B (PB) & 13 \\
\hline Neomycin $(\mathrm{N})$ & 11 \\
\hline \multicolumn{2}{|c|}{ Biopolymer production (qualitative test) } \\
\hline Benedict's test & - \\
\hline Barfoed's test & - \\
\hline Molisch test & - \\
\hline Fehling's test & + \\
\hline
\end{tabular}

3.2. Plant Growth Promotion Assay Using PANCL and MAMCC. Partially purified EPS was used for plant growth promotion assay with Vigna radiata. Dicot Vigna radiata was chosen for study, because it is easy to handle plant having short lifespan and that can be cultivated in pot under laboratory conditions with very few requirements. In plant growth promotion assay, result indicated that EPS produced by organism enhanced two-fold growth of plant Vigna radiata (Figure 3 ). In another species, sporulated MAMCC (mycelium and spores) was collected in sterile glucose saline. $25 \mathrm{~mL}$ spore suspension having 99.25 spores/mL (Figure 4) was sprinkled on pot-II to pot-IV. Pot-I (control) was kept untreated. Enhancement in growth of Vigna radiata was observed and recorded after 17 days of growth (Figures 5-6, Table 3(a)). We have studied effect of consortium of PANCL biopolymer and MAMCC spores for their plant growth promotion ability. Pot-V soil was mixed with PANCL biopolymer and MAMCC spores suspension in 1:1 ratio. Remarkable growth of Vigna radiata was recorded after every $48 \mathrm{~h}$ up to 17 days of growth. Also, it was observed that consortium has increased chlorophyll content (Figure 7). After 17 days,

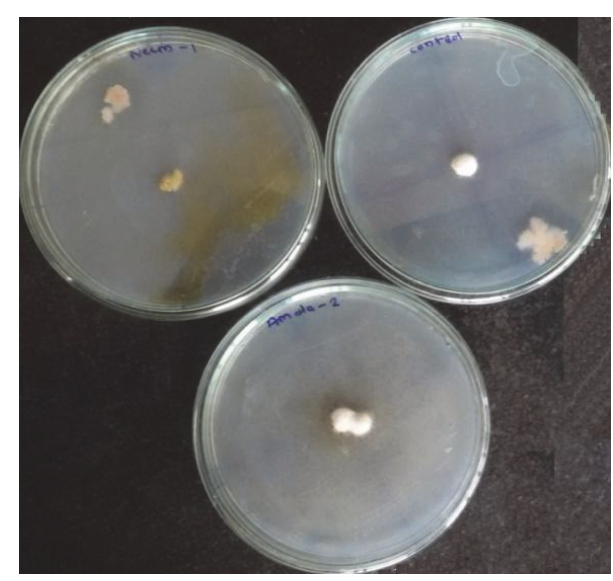

Figure 2: MAMCC: radial growth assay with Neem and KarelaAmla oil.

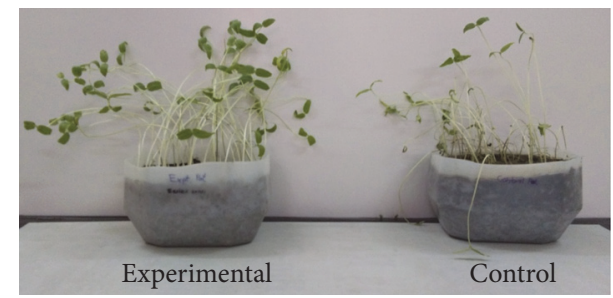

FIGURE 3: PANCL: plant growth promotion assay using PANCL exopolysaccharide.

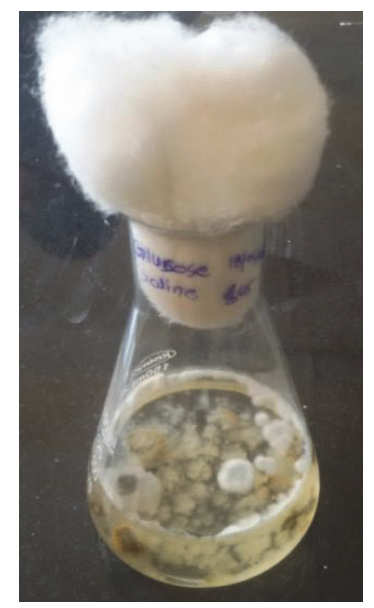

FIGURE 4: MAMCC: sporulation.

all plants (from both control and exp. pot) were taken out and dried at temperature $45^{\circ} \mathrm{C}$ for 48 hours. Wet weight of total 50 plants at the time of harvest was taken for each pot and respective control. Roots were observed for presence root nodules. It was observed that there were no such clear root nodules on toots of Vigna radiata observed. This indicates that enhanced plant growth was incurred due to positive effects of biopolymer and spores. There was considerable increase in dry weight of plant biomass in experimental pot-II and pot-V (Table 3(b)). 


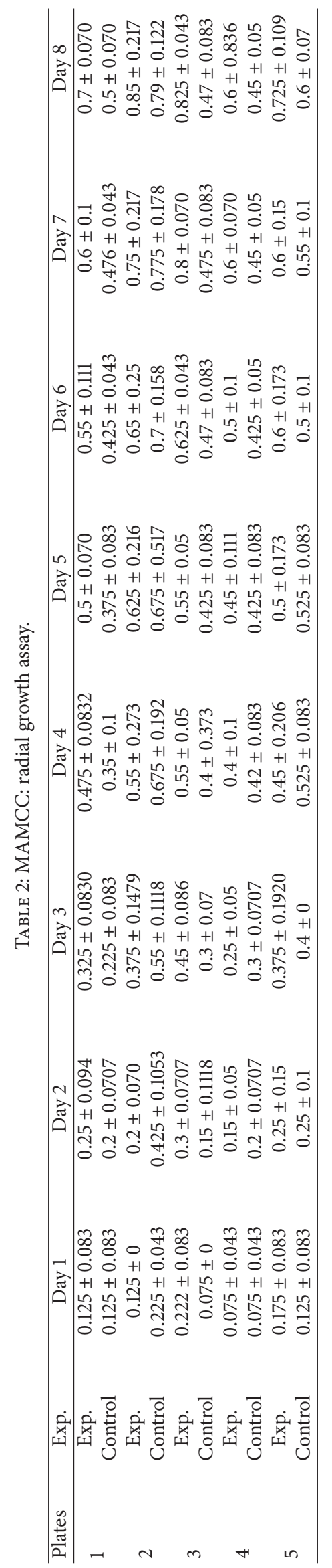


TABLE 3

(a) Plant growth promotion assay using gamma-proteobacterium Pseudomonas aeruginosa NCIM 2945 and entomopathogenic fungus Metarhizium anisopliae MCC 1129.

\begin{tabular}{|c|c|c|c|c|c|c|c|}
\hline \multirow{2}{*}{ Pots number } & \multicolumn{7}{|c|}{ Day } \\
\hline & I-IV & V & VII & IX & XI & XIV & XVI \\
\hline Control I & - & 8.5 & 13.5 & 15.5 & 16.1 & 17.0 & 18.0 \\
\hline Exp. II & - & 8.5 & 12.0 & 15.3 & 16.1 & 17.1 & 18.8 \\
\hline Exp. III & - & 9.7 & 13.6 & 14.1 & 15.4 & 16.3 & 16.8 \\
\hline Exp. IV & - & 7.7 & 11.4 & 14.8 & 15.3 & 16.8 & 17.1 \\
\hline Exp. V & - & 11.0 & 13.0 & 15.3 & 15.6 & 16.7 & 17.1 \\
\hline
\end{tabular}

Note: growth was measured in $\mathrm{cm}$. Exp. V was performed in consortium of PANCL and MAMCC.

(b) Wet weight and dry weight of Vigna radiata plants in a pot experiment after 17 days of growth.

\begin{tabular}{lccc}
\hline Pot number & Number of plants at the time of harvest & Wet weight (gm) & Dry weight (gm) \\
\hline Pot-I (control) & 50 & $13.49 \pm 0.043$ & $2.5 \pm 0.083$ \\
Pot-II (exp.) & 50 & $14.1 \pm 0.14$ & $3 \pm 0.05$ \\
Pot-III (exp.) & 50 & $9.81 \pm 0.07$ & $3.4 \pm 0.05$ \\
Pot-IV (exp.) & 50 & $3.19 \pm 0.05$ & $2.23 \pm 0.04$ \\
Pot-V (exp.) & 50 & $14.6 \pm 0.1$ & $2.81 \pm 0.041$ \\
\hline
\end{tabular}

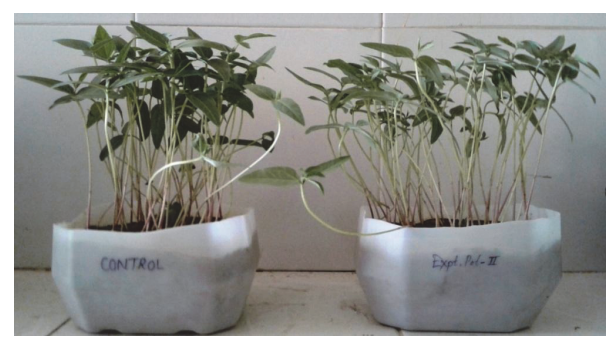

FIGURE 5: PANCL: plant growth promotion assay pot-II.

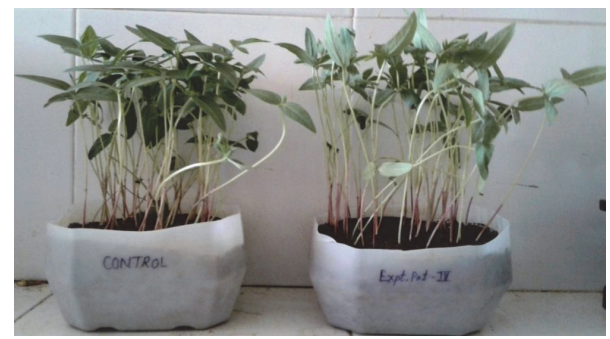

FIGURE 6: PANCL: plant growth promotion assay pot-IV.

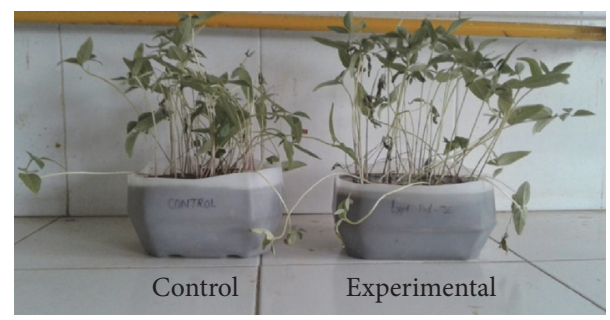

FIGURE 7: Plant growth promotion activity by consortium of PANCL (biopolymer) and MAMCC (fungal spores).

\section{Discussion}

Bacteria that colonize in the rhizospheric soil and at the root zone and promote plant growth are termed as plant growth promoting bacteria. These include many free-living dinitrogen fixers such as Azotobacter, Azospirillum, Bradyrhizobium, Enterobacter, Pseudomonas and Bacilli. Bacterium showing plant growth is frequently reported worldwide by many research groups as potent plant growth promoting rhizobacteria and acts as biofertilizers [17]. There are scarce reports/literature available on Metarhizium anisopliae used itself or its spores as plant growth promoter. Fungal species like Metarhizium robertsii are capable of growing in soil near rhizosphere. Naturally, they shed conidia which adhere to soil and roots. After germination under favorable condition conidia adhered germinated and colonized roots and root zone. There is evidence that Metarhizium grew faster and increase the density of plant root hairs. This indicates that Metarhizium robertsii displays a beneficial endophytic association helpful for the proliferation of root hairs [18]. The experiments performed and results generated in this paper are entirely different. We have combined one bacterial biopolymer and fungal spores. Complete sterilization of the soil killed the resident flora of soil. The sterile soil without microbial flora was used. This also minimized the chances of rhizobium to get place into root nodules of legume Vigna radiata. The proposed experiment in fixed pipeline solves the problem about the growth of plants with least or no microflora present. This entire experiment will be useful for green economy and modern agriculture practices.

\section{Conclusion}

From the results, it was concluded that Pseudomonas aeruginosa NCIM 2945 (PANCL) and Metarhizium anisopliae 
MCC1129 (MAMCC) possess property to enhance the growth of crop plant Vigna radiata. Thus, PANCL and MAMCC may find application agriculture industry, that is, for increased crop yield and forage production.

\section{Competing Interests}

The authors declare that there is no conflict of interests regarding the publication of this paper.

\section{References}

[1] W. H. Gera Hol, T. Martijn Bezemer, and A. Biere, "Getting the ecology into interactions between plants and the plant growthpromoting bacterium Pseudomonas fluorescens," Frontiers in Plant Science, vol. 4, article no. 81, 2013.

[2] W. Jiang, Z. Cheng, B. J. McConkey, and B. R. Glick, "Investigating the role of protein UnkG from the Pseudomonas putida UW4 in the ability of the bacterium to facilitate plant growth," Current Microbiology, vol. 66, no. 4, pp. 331-336, 2013.

[3] M. O'Callaghan, "Microbial inoculation of seed for improved crop performance: issues and opportunities," Applied Microbiology and Biotechnology, vol. 100, no. 13, pp. 5729-5746, 2016.

[4] X. Liao, T. R. O’Brien, W. Fang, and R. J. St. Leger, “The plant beneficial effects of Metarhizium species correlate with their association with roots," Applied Microbiology and Biotechnology, vol. 98, no. 16, pp. 7089-7096, 2014.

[5] A. T. Carolino, A. R. Paula, C. P. Silva, T. M. Butt, and R. I. Samuels, "Monitoring persistence of the entomopathogenic fungus Metarhizium anisopliae under simulated field conditions with the aim of controlling adult Aedes aegypti (Diptera: Culicidae)," Parasites \& Vectors, vol. 7, no. 1, article 198, 2014.

[6] N. Jamil and N. Ahmed, "Production of biopolymers by pseudomonas aeruginosa isolated from marine source," Brazilian Archives of Biology and Technology, vol. 51, no. 3, pp. 457-464, 2008.

[7] M. Ahemad and M. S. Khan, "Alleviation of fungicide-induced phytotoxicity in greengram [Vigna radiata (L.) Wilczek] using fungicide-tolerant and plant growth promoting Pseudomonas strain," Saudi Journal of Biological Sciences, vol. 19, no. 4, pp. 451459, 2012.

[8] S. Gopalakrishnan, A. Sathya, R. Vijayabharathi, R. K. Varshney, C. L. Gowda, and L. Krishnamurthy, "Plant growth promoting rhizobia: challenges and opportunities," 3 Biotech, vol. 5, no. 4, pp. 355-377, 2015.

[9] P. Ganeshamoorthi, T. Anand, V. Prakasam, M. Bharani, N. Ragupathi, and R. Samiyappan, "Plant growth promoting rhizobacterial (PGPR) bioconsortia mediates induction of defense-related proteins against infection of root rot pathogen in mulberry plants," Journal of Plant Interactions, vol. 3, no. 4, pp. 233-244, 2008.

[10] B. N. Rekadwad and A. P. Pathak, "First report on revelatory prokaryotic diversity of Unkeshwar hot spring (India) having biotechnological potential," Indian Journal of Biotechnology, vol. 15, pp. 195-200, 2016.

[11] K. R. Aneja, Experiments in Microbiology, Plant Pathology and Biotechnology, New Age International, New Delhi, India, 2003.

[12] R. Gyawali and S. A. Ibrahim, "Natural products as antimicrobial agents," Food Control, vol. 46, pp. 412-429, 2014.
[13] A. K. Asok, P. A. Fathima, and M. S. Jisha, "Biodegradation of linear alkylbenzene sulfonate (LAS) by immobilized Pseudomonas sp." Advances in Chemical Engineering and Science, vol. 5, no. 4, pp. 465-475, 2015.

[14] C. M. Nichols, S. G. Lardière, J. P. Bowman, P. D. Nichols, J. A. E. Gibson, and J. Guézennec, "Chemical characterization of exopolysaccharides from Antarctic marine bacteria," Microbial Ecology, vol. 49, no. 4, pp. 578-589, 2005.

[15] M. Rajkumar, N. Ae, M. N. V. Prasad, and H. Freitas, "Potential of siderophore-producing bacteria for improving heavy metal phytoextraction," Trends in Biotechnology, vol. 28, no. 3, pp. 142149, 2010 .

[16] B. N. Rekadwad, "Growth promotion of crop plants by Methylobacterium organophilum: efficient bio-inoculant and biofertilizer isolated from mud," Research in Biotechnology, vol. 5, no. 5, pp. 1-6, 2014.

[17] J. K. Vessey, "Plant growth promoting rhizobacteria as biofertilizers," Plant and Soil, vol. 255, no. 2, pp. 571-586, 2003.

[18] R. K. Sasan and M. J. Bidochka, "The insect-pathogenic fungus Metarhizium robertsii (Clavicipitaceae) is also an endophyte that stimulates plant root development," American Journal of Botany, vol. 99, no. 1, pp. 101-107, 2012. 


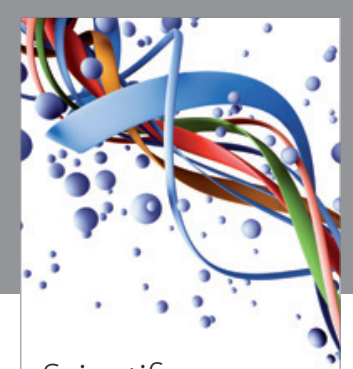

Scientifica
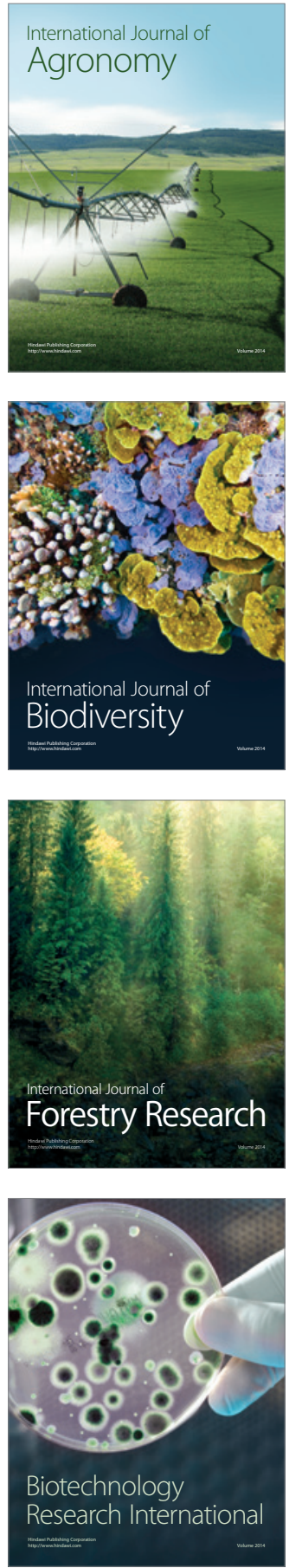
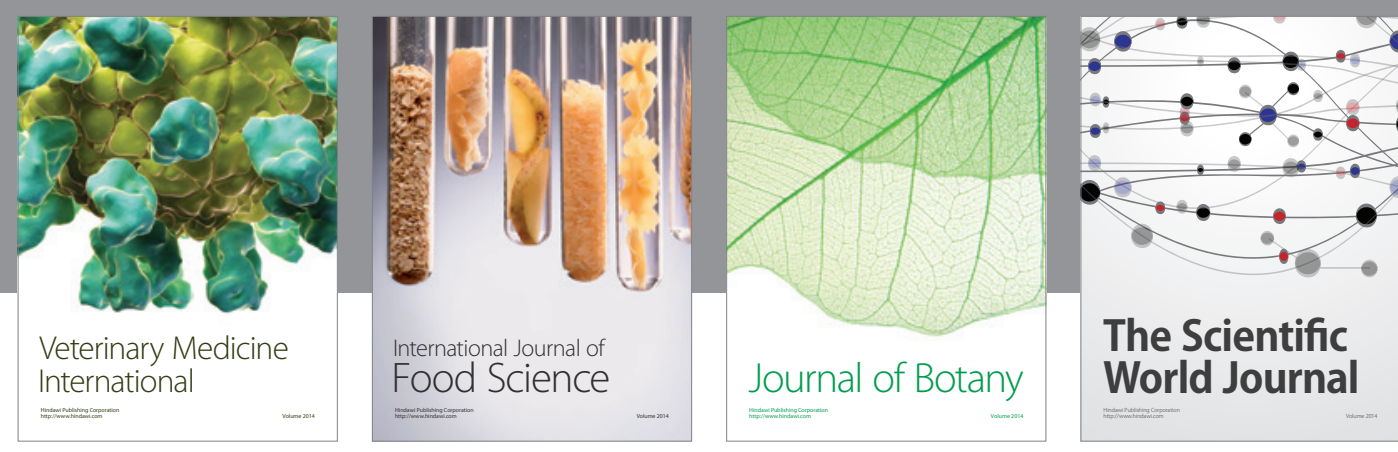

The Scientific

\section{World Journal}

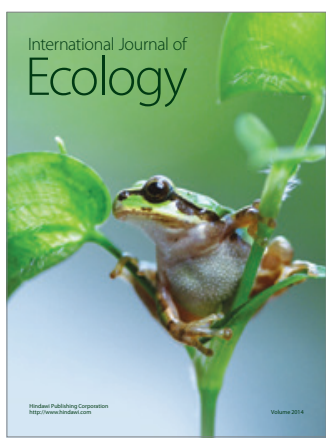

\section{Hindawi}

Submit your manuscripts at

http://www.hindawi.com
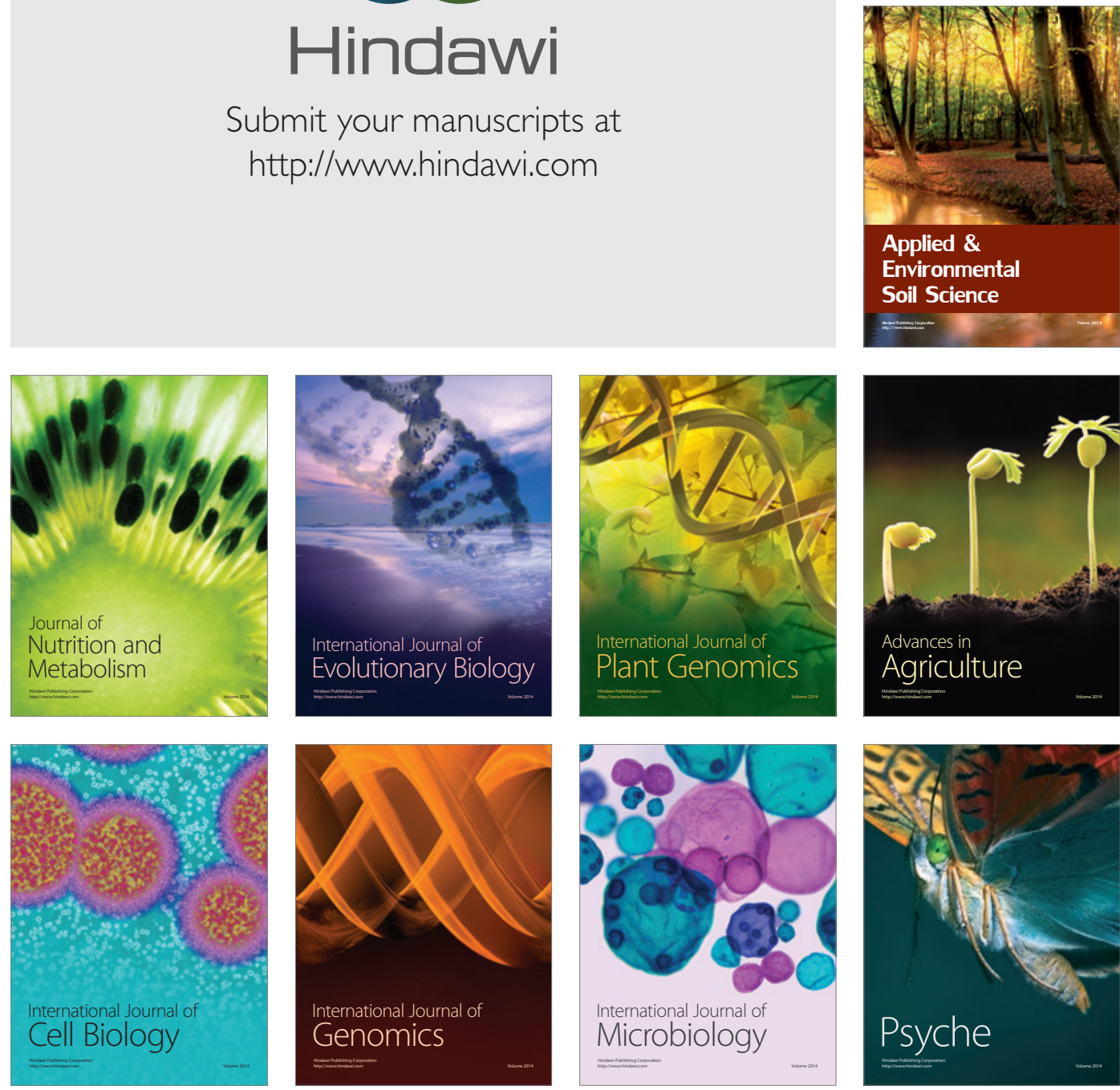
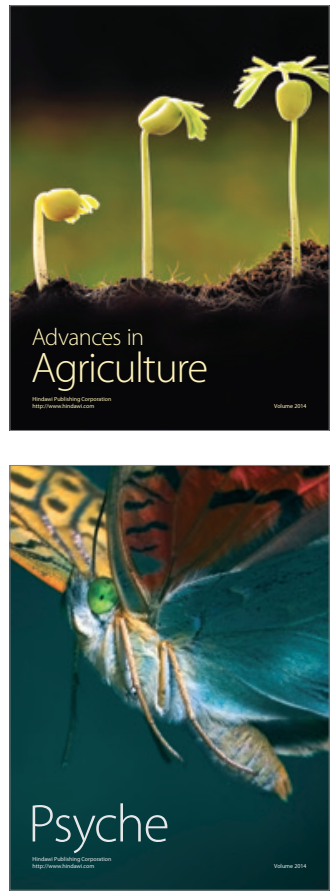